\title{
Co-infection of human parvovirus B19 with Plasmodium falciparum contributes to malaria disease severity in Gabonese patients
}

Nguyen L Toan ${ }^{1,2+}$, Bui T Sy ${ }^{2,7+}$, Le H Song ${ }^{3}$, Hoang V Luong ${ }^{2}$, Nguyen T Binh ${ }^{2}$, Vu Q Binh ${ }^{4}$, Reinhard Kandolf', Thirumalaisamy P Velavan ${ }^{5+}$, Peter G Kremsner ${ }^{5,6+}$ and C-Thomas Bock ${ }^{1,7^{*}+}$

\begin{abstract}
Background: High seroprevalence of parvovirus B19 (B19V) coinfection with Plasmodium falciparum has been previously reported. However, the impact of B19V-infection on the clinical course of malaria is still elusive. In this study, we investigated the prevalence and clinical significance of B19V co-infection in Gabonese children with malaria.

Methods: B19V prevalence was analyzed in serum samples of 197 Gabonese children with P. falciparum malaria and 85 healthy controls using polymerase chain reaction (PCR), enzyme-linked immunosorbent assay (ELISA), and direct DNA-sequencing.

Results: B19V was detected in 29/282 (10.28\%) of Gabonese children. B19V was observed more frequently in P. falciparum malaria patients $(14.21 \%)$ in comparison to healthy individuals $(1.17 \%)(P<0.001)$. Notably, the mild-malaria group revealed significantly lower hematocrit levels in B19V/P. falciparum co-infection than in $P$. falciparum mono-infection $(P<0.05)$. Genetic analysis revealed a predominance of B19V genotype-1 $(71.43 \%)$ in the studied population. However, B19V-genotype 2 was observed significantly more often in children with severe-malaria than in mild-malaria $(P=0.04)$.

Conclusion: Our findings reveal that B19V-infection is frequent in Gabonese children with P. falciparum malaria and signifies a possible contribution of B19V on the clinical course of malaria in a genotype-dependent manner. B19V co-infection should be considered as a additional diagnostic measure in malaria patients with life threatening anemia.
\end{abstract}

Keywords: Erythrovirus, Human parvovirus B19, P. falciparum, Malaria, Co-infection, Gabonese children

\section{Background}

Malaria is one of the major causes of morbidity and mortality in tropical and sub-tropical countries and is caused by the protozoan parasites of the genus Plasmodium while Plasmodium falciparum (P. falciparum) being the most virulent species [1].

$P$. falciparum infected individuals show different clinical phenotypes, which range from asymptomatic infections to severe forms of malaria. The clinical resolution

\footnotetext{
* Correspondence: bockc@rki.de

${ }^{\dagger}$ Equal contributors

'Department of Molecular Pathology, Institute of Pathology and Neuropathology, University of Tuebingen, Tuebingen, Germany

${ }^{7}$ Robert Koch Institute, Nordufer 20, D-13353 Berlin, Germany

Full list of author information is available at the end of the article
}

is influenced by multitude of host and parasite factors [2]. Recent studies have underlined the importance of co-infection with human Parvovirus B19 (B19V) in the etiology and pathogenesis of $P$. falciparum malaria both in adults and in children [3-8]. The B19V infection occurs worldwide, with more than $50 \%$ are infected with B19V during early childhood with highest reported cases among children from tropical countries [7,9].

B19V belongs to the genus Erythrovirus within the family of Parvoviridae [10]. Parvoviruses are non-enveloped DNA viruses that can ably infect mammals [10]. An acute B19V-infection can cause an impaired erythropoiesis [4]. B19V can have a diverse spectrum of clinical manifestations depending on the hematological and the

\section{Biomed Central}


immunological status of the host. Acute B19V-infection can be causative for erythema infectiosum (fifth disease), hydrops fetalis, and aplastic anemia in individuals with underlying hemolysis [11]. Other manifestations include arthritis [12,13], myocarditis [14,15], vasculitic syndromes [16], neurological disorders [17], and hepatic inflammation $[18,19]$.

B19V-infection has been demonstrated to elevate severe anemia caused by $P$. falciparum among young children in the Republic of Nigeria [7]. The B19V-infection outbreak in Nigeria reported that $54 \%$ of children with $P$. falciparum associated severe anemia (hematocrit level, <20\%) showed an evidence of B19V-infection [7]. Similar studies from Ghana, Papua New Guinea, and Kenya support the finding that B19V can play an important role in the etiology of severe anemia in children living in malaria endemic areas $[8,20,21]$. However, other studies from Malawi [22] and Kenya [23] observed little evidence of acute B19V-infection in severe anemia in children with malaria.

In the present case-control study we utilized 282 healthy and $P$. falciparum infected Gabonese children from sub-Sahara Africa. We aim to investigate the prevalence of $\mathrm{B} 19 \mathrm{~V}$-infection from this malaria endemic area and further sought to determine the relationship of B19V and P. falciparum co-infection on the etiopathogenesis of P. falciparum malaria.

\section{Methods}

\section{Study subjects}

282 children were recruited at the Albert Schweitzer Hospital, Lambaréné, Gabon, and the Centre Hospitalier de Libreville, Libreville, Gabon. The investigated cohort is from a matched pair, case-control study, to compare severe and mild malaria in Gabon. Details of the study cohort are as described elsewhere [24,25]. Serum samples of the patients were cryo-freezed and stored as different aliquots at $-80^{\circ} \mathrm{C}$ until use. 197/282 individuals were infected with $P$. falciparum with well-characterized clinical profiles (Table 1). 85/282 children served as healthy controls and had no evidence and/or clinical signs of $P$. falciparum infection during recruitment [26]. The healthy control individuals were chosen of the same sex, age, and locality and the exclusion criteria were asymptomatic P. falciparum infection and indications for concurrent diseases and malnutrition. Among the 197 P. falciparum infected children, individuals were further classified in two sub-groups either as severe $(n=97)$ or mild malaria $(n=100)$ based on clinical signs, symptoms and parasite load with clinical profiles as shown in Table 1. Clinical presentation of the severity of P. falciparum infection has been described previously [25,27-29].

Severe malaria was defined as severe anemia (hemoglobin $<50 \mathrm{~g} / \mathrm{L}$ ) and/or hyperparasitemia (> 250,000
Table 1 Characteristics of Gabonese children with $P$. falciparum malaria according clinical presentation

\begin{tabular}{lccc}
\hline Characteristics & $\begin{array}{c}\text { Mild malaria } \\
(\mathbf{n = 9 7})\end{array}$ & $\begin{array}{c}\text { Severe malaria } \\
(\mathbf{n = 1 0 0})\end{array}$ & $\boldsymbol{P}$ \\
\hline Age (Month) & 44.90 & 44.23 & n.s. \\
Male/female & $35 / 62$ & $39 / 61$ & n.s. \\
$\begin{array}{l}\text { Systolic blood pressure } \\
(\mathrm{mmHg})\end{array}$ & 103 & 93 & $<0.01$ \\
$\begin{array}{l}\text { Heart frequency (beats/ } \\
\text { min) }\end{array}$ & 120 & 130 & $<0.001$ \\
$\begin{array}{l}\text { Respiratory rate } \\
\text { (breaths/min) }\end{array}$ & 35 & 41 & $<0.001$ \\
$\begin{array}{l}\text { Hematocrit (Proportion } \\
\text { of 1.0) }\end{array}$ & 3290.6 & 2143.5 & $<0.0001$ \\
Hemoglobin (g/L) & $>80$ & $<50$ & $<0.0001$ \\
Lactate (mmol/L) & 2.4 & 2.9 & $<0.05$ \\
Parasite $\times$ 1000/ $\mu \mathrm{L}$ & 26.492 & 407.08 & $<0.0001$ \\
Schizontaemia (n) & 0 & 24 & $<0.001$ \\
\hline ns. & & & \\
\end{tabular}

n.s. = not significant, values are given as median, values for male/female are given as numbers.

parasites/ml corresponding to $>10 \%$ infected erythrocytes) and facultative signs of severe malaria, such as cerebral malaria, convulsions, hypoglycemia, and respiratory distress.

Individuals with mild malaria were chosen from patients of the same sex, age, and locality, and admitted as soon as the severe cases were enrolled for this study. For mild malaria, the following criteria were considered: parasitemia between $1,000 / 1$ and 50,000/l on admission, no schizonts in the periphery, malarial pigment containing circulating leukocytes $<50 / \mu \mathrm{l}$, hemoglobin $>80 \mathrm{~g} / \mathrm{L}$, platelets $>50 / \mathrm{nl}$, leukocytes $<12 / \mathrm{nl}$, and blood glucose $>50 \mathrm{mg} /$ $\mathrm{dl}$ (Table 1). Exclusion criteria were signs of severe malaria and/or other acute infections and prior hospitalization for any reasons to exclude possible severe malaria in the history and intake of antimalarial drugs within the preceding weeks.

\section{Polymerase chain reaction (PCR)}

Nucleic acid was extracted from patient sera using High Pure Viral Nucleic Acid Kit (Roche, Grenzach-Wyhlen, Germany) according to the manufacturer's instruction. The detection of B19V-DNA was tested by nested polymerase chain reaction (nPCR) as described previously using primer pairs specific for the VP1/VP2-coding regions [30]. All samples tested positive for B19V were reconfirmed with an independent second round of PCR which amplified the NS1/VP1u-region [31]. PCR conditions employed were described as in previous studies [31]. In order to prevent assay contamination, sample processing (DNA-extraction, template preparation, centrifugation, aliquoting, and master mix preparation) and PCR-amplification were performed in 
dedicated laboratory facilities certified for molecular diagnostics and especially for PCR, using standard precautions. Specificity of PCR products were reconfirmed by DNA-sequencing. The B19V-DNA sequences were aligned with published B19V-genome sequences [GenBank accession number: genotype 1A: M13178, genotype 1B: DQ357064, genotype 2: AY064476 and AY044266; and genotype 3: AX003421, AY083234].

\section{Quantitative real-time PCR for B19V-DNA}

The B19V-DNA load was determined in the serum by B19V-specific quantitative real-time PCR (qPCR) using the GeneAmp 7300 sequence analyser (TaqMan Sequence Detection System; Applied Biosystems Perkin-Elmer, Foster City, CA) The primers, probes and program conditions were used as described previously [30,32]. The specificity and sensitivity of the B19V-qPCR was determined using the WHO international standards for B19V-DNA (NIBSC Code 99/800) containing $10^{5} \mathrm{IU} / \mathrm{ml}$ B19V DNA along with integrated B19V-negative control plasmids. In order to standardize the $\mathrm{qPCR}$, increasing dilutions of B19V plasmid DNA $\left(6.5 \times 10^{4}\right.$ to $6.5 \times 10^{1}$ $\mathrm{B} 19 \mathrm{~V} \mathrm{IU} / \mathrm{ml}$ ) were included. The lower sensitivity of the B19V-qPCR assay was found to be $2 \times 10^{2} \mathrm{IU} / \mathrm{ml}$. Samples were analyzed in duplicates including extraction of nucleic acids.

\section{DNA sequence analysis}

DNA fragments spanning the coding NS1/VP1u region from nt 2355-2690 (nt. position according to AF162273) were amplified by nPCR as described previously for all B19V-DNA positive samples [19,31]. The sequencing reaction was performed with $5 \mu$ of purified PCR products, $2 \mu \mathrm{l}$ BigDye Terminator Cycle Sequencing reaction (Life Technologies Corp., USA), and 15 pmol primer pairs. The PCR products were sequenced in sense and antisense direction using primers as described previously [31]. The primers used for sequencing were sense (n-P5F) 5'CGTGAACTGTTAGTTGGGGTTGA-3' and antisense (n-P5R) 5'-AATTGCTGATACACAGCTTTAG-3'. The DNA sequences were analyzed using ABI Prism Genetic Analyser 3100C (Applied Biosystems, Foster City, USA).

\section{B19V serology evaluation}

Anti-B19V-IgM and anti-B19V-IgG (VP1/VP2) were analyzed by enzyme-linked immunosorbent assay (ELISA) (Parvovirus B19-IgM; Parvovirus B19-IgG, DxSelect ${ }^{\mathrm{mm}}$ FocusDiagnostics, Germany) according to the manufacturer's instructions. An Index Value $>1.20$ measured of the serum samples in the ELISA assay indicated the presence of B19V IgG or IgM antibodies. The anti-B19V IgM ELISA assay has a reported sensitivity of $89 \%$ and specificity of $98 \%$ and the anti-B19V IgG ELISA assay a sensitivity of $96 \%$ and specificity of $97 \%$, respectively.

\section{B19V-genotype analysis}

B19V-sequences were aligned using CLUSTALW (http:// www.ebi.ac.uk/Tools/msa/clustalw2/) and GENEDOC2.5 (http://www.psc.edu/biomed/genedoc). Genetic distances were calculated using the Kimura two-parameter model incorporated into the MEGA5.0 [33]. Phylogenetic trees were reconstructed by MEGA5.0 using the Neighbour-Joining method [34]. The robustness of inferred relationships was assessed with bootstrapping based on 1000 replicate data sets (bootstrap value $<40$ were not shown on the tree).

B19V-sequences available from the GenBank database were used as reference sequences for sequence alignment [GenBank accession numbers: genotype 1A: AB030694, AF113323, AF162273, and M13178; genotype 1B: DQ357064, DQ357065, and KF417555; genotype 2: AY064476 and AY044266; and genotype 3: AX003421, AY083234]. The GenBank accession numbers for the nucleotide sequences of $\mathrm{B} 19 \mathrm{~V}$-samples determined in this study are from KF309501 to KF309528.

\section{Statistical analysis}

Statistical analysis was performed using Statview 4.57 (www.statview.com),JMP Statistical Discovery Software, version 5.0.1 (www.jmp.com), and Prism5 (version 5.01, GraphPad Software, San Diego California USA, www. graphpad.com). A $P$-value $<0.05$ was considered to be statistically significant in all statistical computations. We computed Fisher's exact test and the Mann-Whitney $U$ test and Spearman's Rho test for our analysis as accordingly.

\section{Ethical approval}

The study was approved by the ethics committee of the International Foundation for the Albert Schweitzer Hospital in Lambaréné, Gabon. Informed written consent for participation in the study was obtained from a parent or guardian of the children.

\section{Results}

\section{Prevalence of B19V-DNA and anti-B19V-antibodies}

In order to determine the prevalence of B19V-DNA in sera of the $P$. falciparum malaria patients we performed nPCR amplifying the B19V VP1/VP2 and B19V NS1/ VP1u region. Representative nPCR results using B19VNS1/VP1u specific primers generating a 336bp B19VNS1/VP1 fragment are shown in Figure 1A. NS1/VP1u amplicons were confirmed by DNA-sequencing (Figure 1B). Sequencing analysis revealed that sequences differ between the $\mathrm{B} 19 \mathrm{~V}$ isolates, thereby excluding crosscontamination of patient samples representing patientspecific B19V isolates.

Investigation on the prevalence of $\mathrm{B} 19 \mathrm{~V}$ in patients with mild, severe $P$. falciparum malaria and in controls showed that B19V-DNA were detectable in $29 / 282$ 


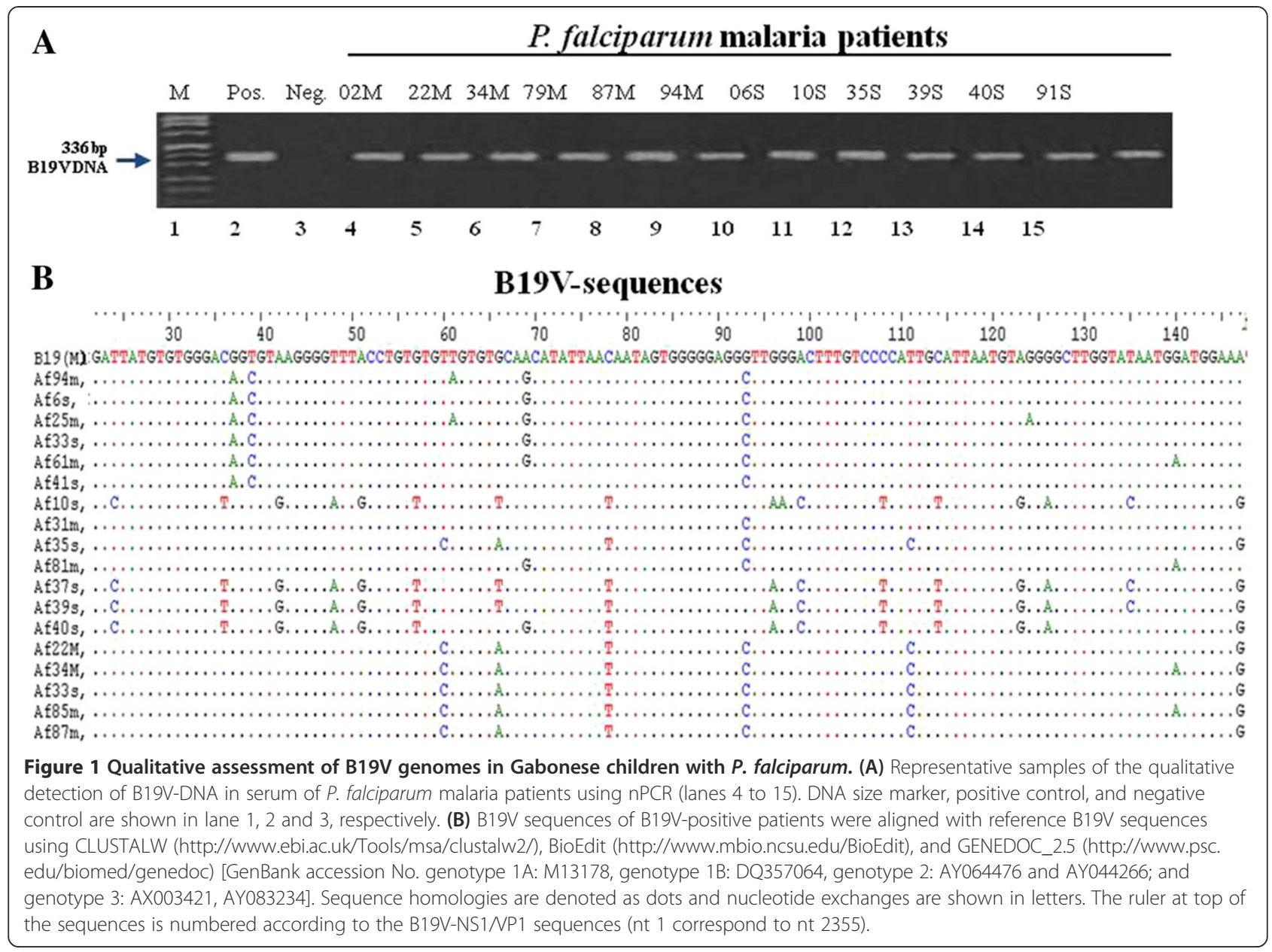

(10.28\%) of Gabonese children. The prevalence of B19V-DNA was significantly higher in patients with P. falciparum malaria compared to healthy subjects (14.21\% vs. $1.17 \%, P<0.001$; Figure $2 \mathrm{~A})$. However, the proportion of B19V-DNA detection was significantly higher in the severe and mild malaria patient groups in comparison to the healthy subjects following the profile: healthy control < mild malaria < severe malaria $(1.17 \%$, $12.37 \%$, and $16 \%$, respectively; Figure $2 \mathrm{~B})(P<0.01$ and $P<0.001$; respectively).

Twenty-eight B19V-DNA positive samples of patients with $P$. falciparum were examined for anti-B19V-IgM and anti-B19V-IgG. In total, B19V-IgM and B19V-IgG antibodies were detected in 20/28 (71.43\%) and 19/28 (67.86\%) serum samples, respectively. Overlapping antiB19V-IgM and anti-B19V-IgG were detected in 11/28 (39.28\%) cases, whereas 9/28 (32.14\%) patients were antiB19V-IgM-positive and anti-B19V-IgG-negative and 8/28 (28.57\%) of patients were anti-B19V-IgG-positive and anti-B19V-IgM-negative.

Additionally simultaneous detection of B19V-DNA and B19V-IgM antibodies in 71,4\% (20/28) of the serum samples is indicative for an acute or recently acute B19V-infection rather than a persistence of B19V-DNA.

B19V-loads, parasitemia of P. falciparum, and anemia in patients with $\mathrm{P}$. falciparum malaria

In order to examine the B19V replication levels of B19V/ $P$. falciparum co-infections, we examined B19V loads in the serum of the Gabonese children with malaria. The B19V loads in sera of B19V/P. falciparum co-infected patients were $3.08 \log 10$ (range 1.65-4.83) IU/ml. No significant differences of the B19V loads of sera of mild malaria patients (median, $2.48 \log 10 \mathrm{IU} / \mathrm{ml}$ [range 1.65$4.83 \mathrm{IU} / \mathrm{ml}]$ ) compared to severe malaria patients (median, $3.42 \log 10 \mathrm{IU} / \mathrm{ml}$ [range 1.76-4.11 IU/ml]) were observed, $P>0.05$ (Figure 3).

Additionally, the parasitemia of Plasmodium spp. did not differ significantly in B19V/P. falciparum co-infected patients compared to mono-infections of $P$. falciparum $(201.910 \pm 184.018$ vs. $201.570 \pm 276.973$ parasites $/ \mu \mathrm{L}$, respectively, $P>0.05$; Table 1 ). However, in the mild malaria group the parasitemia of $P$. falciparum patients co-infected with B19V was marginally higher (41.900 \pm 


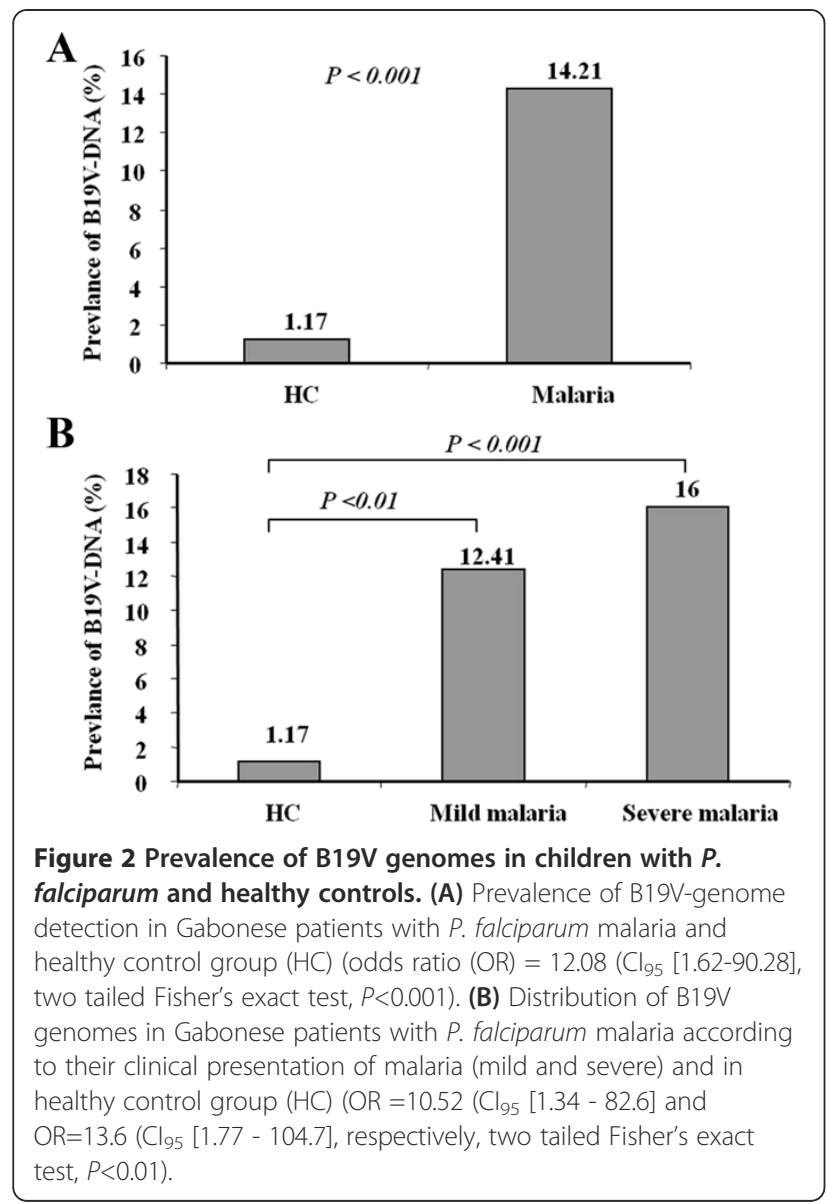

38.818 parasites $/ \mu \mathrm{L})$ compared to $P$. falciparum monoinfection ( $23.600 \pm 31.277$ parasites $/ \mu \mathrm{L} ; P=0.06)$.

The investigation of hematocrit levels in mild malaria patients revealed that hematocrit levels were significantly lower in patients with B19V/P. falciparum co-infection

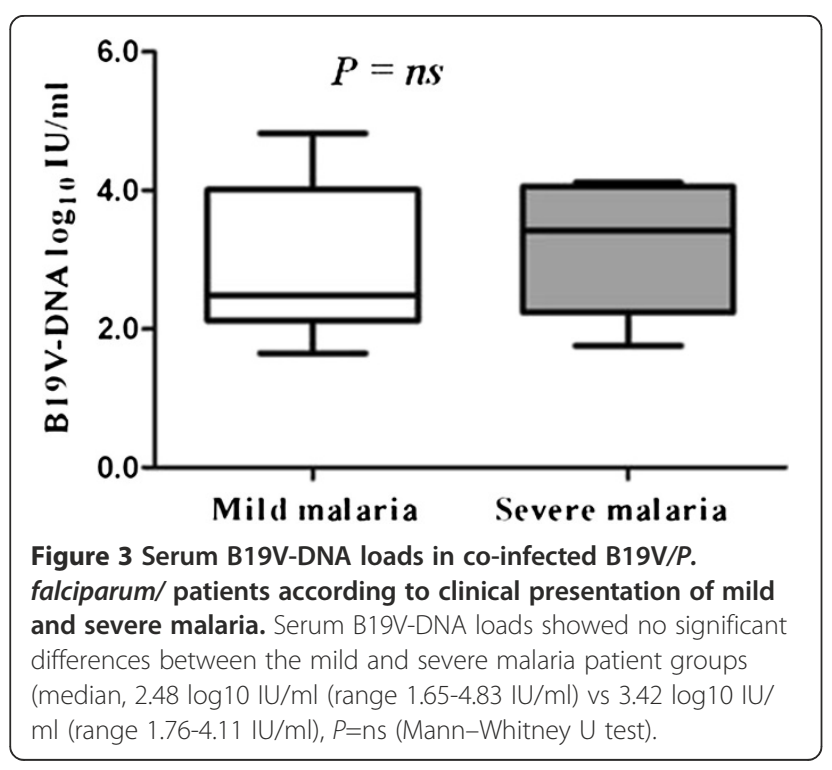

in comparison to $P$. falciparum mono-infection $(P<0.05$; Figure 4A). However, in severe malaria patients hematocrit levels were not altered when compared to $\mathrm{B} 19 \mathrm{~V} / P$. falciparum coinfection with $P$. falciparum mono-infection $(P>0.05$; Figure $4 \mathrm{~B})$.

\section{Distribution of B19V-genotypes in Gabonese children}

Currently, three Erythrovirus genotypes (genotype 1, 2 and 3) have been described [35,36] whereas B19Vgenotype 1 seems to be the predominant genotype worldwide in recent years [37]. In order to examine the distribution of B19V-genotypes in Gabonese children with $P$. falciparum malaria we analysed B19V-positive samples of the patient cohort using molecular epidemiological methods. Sequencing analysis of the subgenomic B19V NS1/VP1u region indicated that both B19V genotypes 1 and 2 were detectable in Gabonese children. However, B19V-genotype 1 was observed to be more frequent than genotype 2 (20 of $28(71.43 \%)$ vs. 8 of $28(28.57 \%)$, whilst genotype 3 could not be detected in the study population.

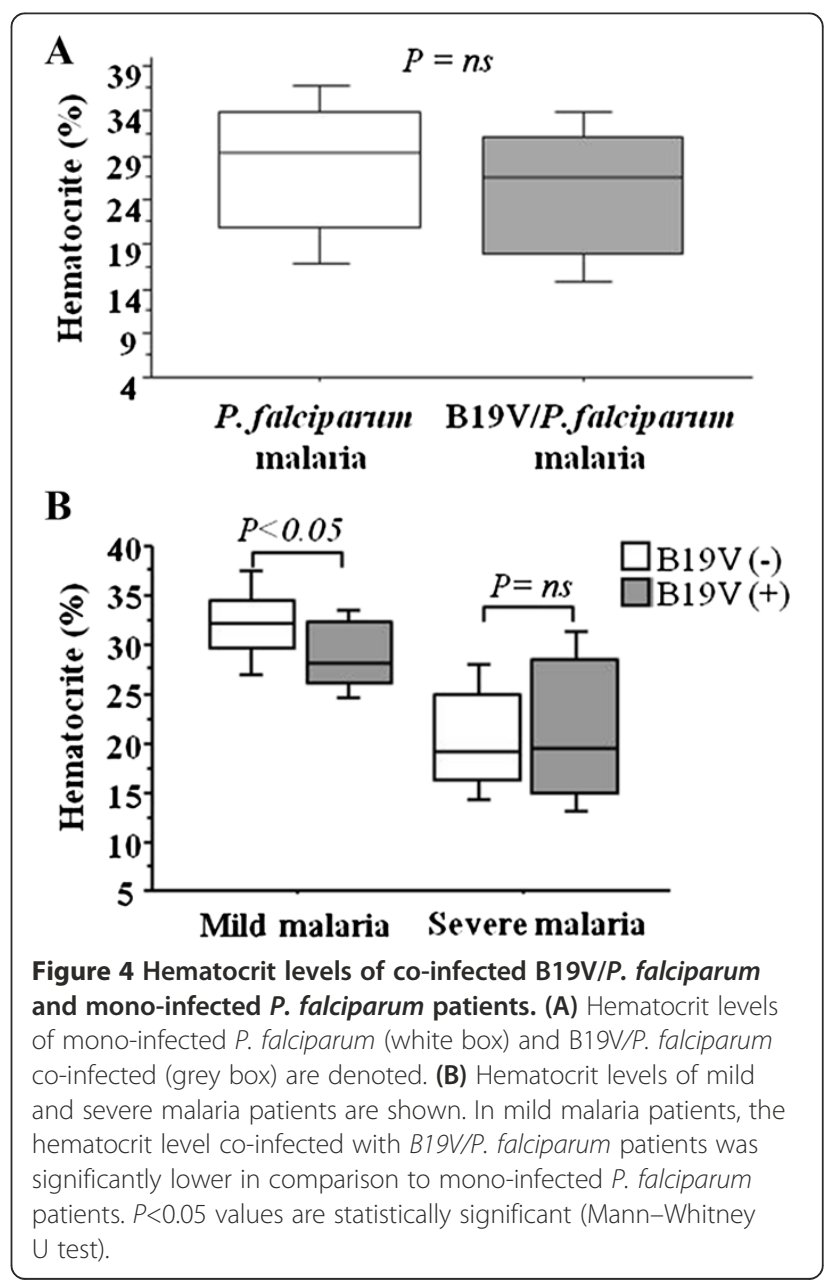


To determine the contribution of B19V-genotypes on the course of P. falciparum malaria (mild and severe), we examined the distribution of B19V-genotypes in serum of $P$. falciparum malaria patients. No significant differences in the levels of parasitemia, hemoglobin and hematocrit in the serum of the malaria patients across the different B19V genotypes were observed (data not shown). Additionally, B19V-DNA loads showed no significant differences $(P>0.05$; Figure $5 \mathrm{~A})$. However, B19V-genotype 2 was more significantly detected in patients with severe malaria (7/16) compared to patients with mild malaria (1/12) (Figure 5B; $P<0.05$; one tailed Fisher's exact test).

Recently, our studies demonstrated that B19V-genotype 1 can be classified into at least two B19V sub-genotypes 1 ,
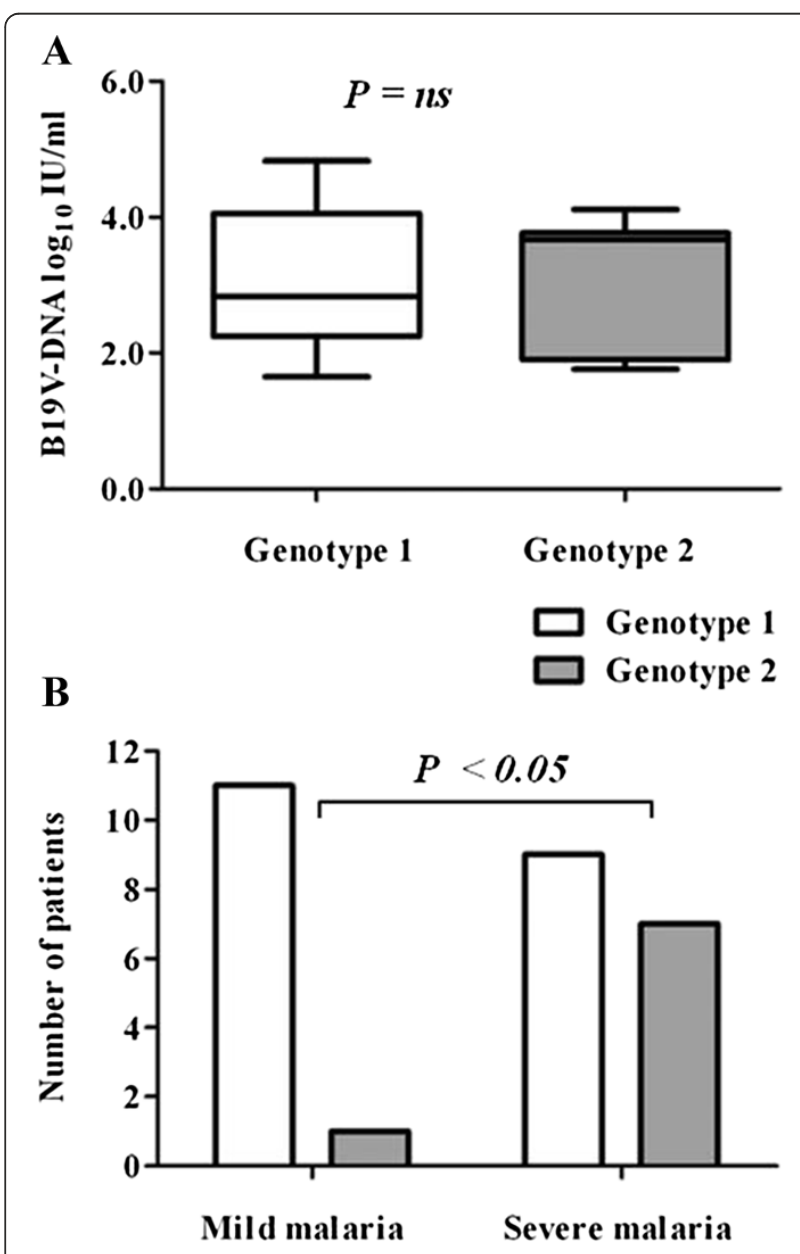

Figure 5 B19V genotype-specific distribution and viral loads in B19V/P. falciparum coinfected malaria patients. (A) B19V genotype-specific viral loads was not significantly different between the malaria patient groups (median, $2.83 \log 10 \mathrm{IU} / \mathrm{ml}$ (range 1.65-4.83 IU/ml) vs $3.67 \mathrm{log} 10 \mathrm{IU} / \mathrm{ml}$ (range 1.76-4.11 IU/ml), $P=$ ns (Mann-Whitney $U$ test). (B) Prevalence of B19V genotypes 1 and 2 in mild and severe malaria patient groups. The prevalence of B19V-genotype 2 was significantly higher in severe malaria than in mild malaria $\left(\mathrm{OR}=8.56\left(\mathrm{Cl}_{95}[0.88-83.1]\right.\right.$, one-tailed Fisher's exact test, $P<0.05)$.
B19V-1A and B19V-1B [31]. In order to analyze the B19V sub-genotype in Gabonese children the sub-genomic NS1/VP1u region of the B19V-positive patient samples were compared to $\mathrm{B} 19 \mathrm{~V}$ reference sequences from the database using phylogenetic analysis. Nineteen B19Vsequences from the studied Gabonese clustered in a single clade of B19V-genotype 1A (67.85\%) whereas one $\mathrm{B} 19 \mathrm{~V}$ isolate clustered with the other clade of B19Vsubgenotype 1B (Af22m [GenBank: KF309508]). Eight B19V-sequences clustered with the genotype 2 reference group (28.57\%; Figure 6A).

The genetic distances among the newly detected B19Vand reference strains were calculated based on the Kimura two-parameter model using MEGA5.0 software. The results of the genetic distance analysis of the sub-genomic $\mathrm{B} 19 \mathrm{~V}$ NS1/VP1u region of the B19V samples are shown in Figure 6B. The genetic distances among the B19V-strains within each $\mathrm{B} 19 \mathrm{~V}$-genotype were very low, ranging from 0.009 to 0.063 for B19V-genotype 1 (1A and 1B)(Figure 6B, No. 1-10) and from 0.000 to 0.056 for B19V-genotype 2 (Figure 6B, No 11-18) while B19V-genotype 3 was not detected in our study. Further analysis showed that the genetic distances determined in B19V sub-genotypes 1A and $1 \mathrm{~B}$ were also low with highest value of 0.063 (Figure 6B, No 4/genotype 1A and No 10/genotype 1B). In contrast, the mean distance between different B19Vgenotypes was higher than the mean intra-genotypic divergence (Figure $6 \mathrm{~B},>0.129$ ). Overall, the average genetic distance was 0.086 among all B19V-genotypes. The genotypic identification of B19V-strains was completely accurate $(100 \%)$ using both the diagnostic nucleotide and distance-based/phylogenetic approaches.

\section{Discussion}

Malaria due to $P$. falciparum infection still pose major health problem in developing countries and in many sub-Saharan countries such as Gabon. In regions with high endemicity for $P$. falciparum infection, the majority of children with malaria present a mild form of the disease. A small proportion of individuals infected with $P$. falciparum develop severe forms of malaria with a higher risk of mortality and morbidity [38]. The association of B19V with aplastic crisis in hemolytic diseases such as sickle cell anemia is well reported, however, their role in coinfection with $P$. falciparum malaria is yet controversial. Anemia in malaria is multifactorial and mainly due to haemolysis and dyserythropoiesis [39]. Recently, two studies in children of Papua New Guinea showed that certain common infections, and especially B19Vinfection can play a critical role in the etiology of severe anemia besides other factors, such as malnutrition and iron deficiency, in a highly endemic area for malaria $[21,40]$. This finding was further supported by yet another study showing that high B19V IgM levels were 


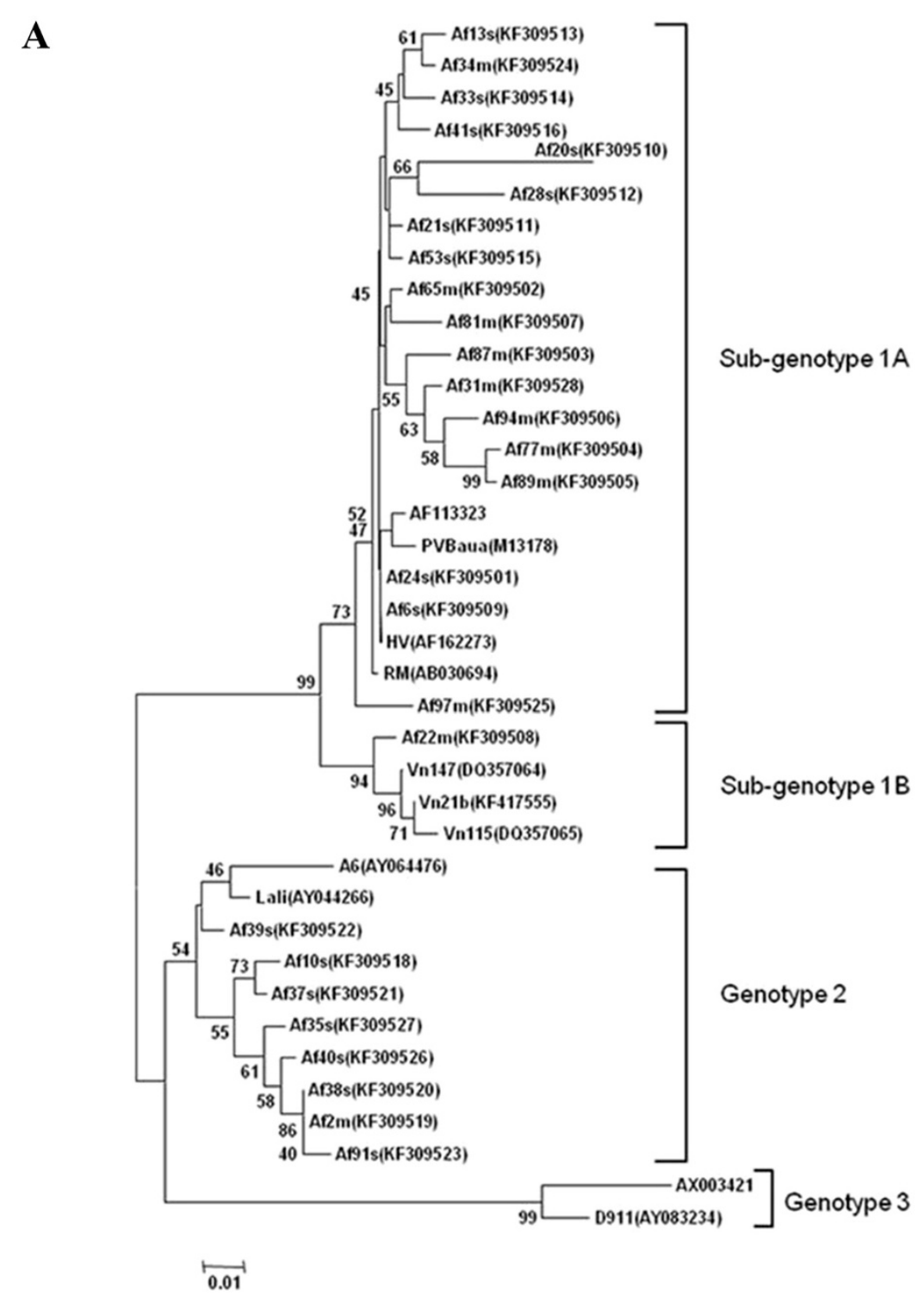

B Genetic distance calculation (Kimura two-parameter model) of B19V-strains

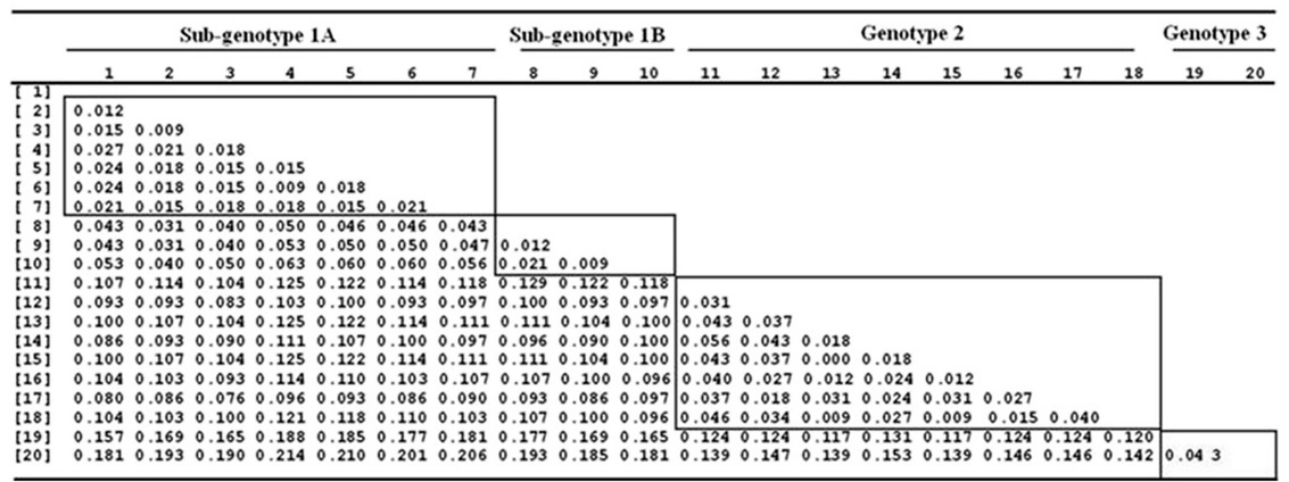

Figure 6 (See legend on next page.) 


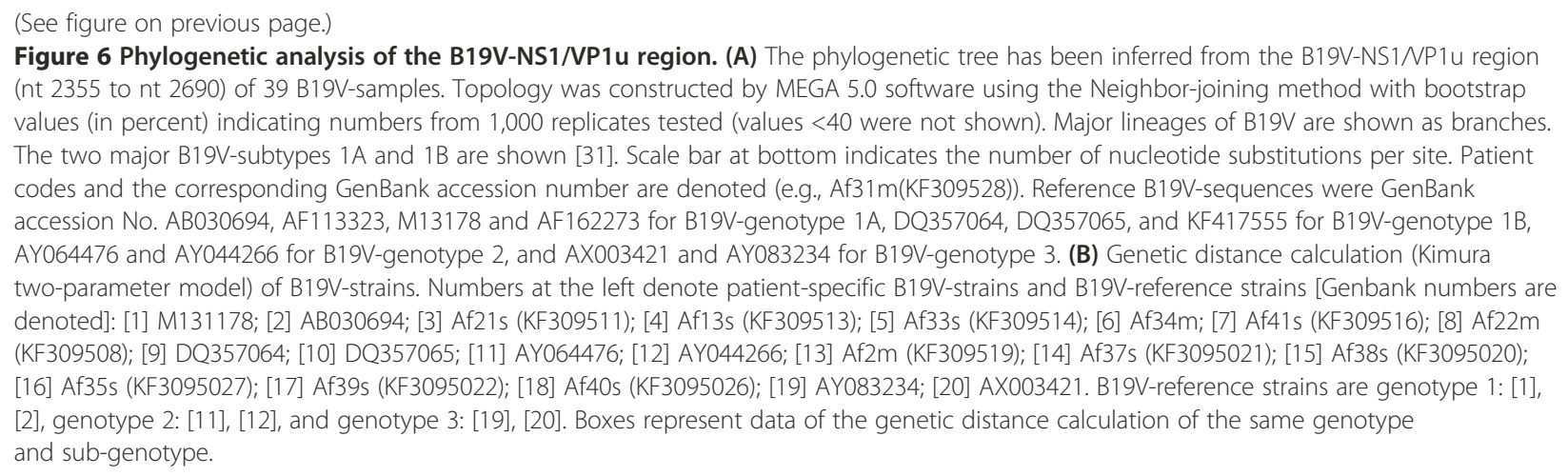

significantly associated with severe anemia in Kenyan children [20]. B19V-infection can result in severe anemia since B19V selectively inhibits and lysates actively replicating erythroid progenitor cells $[11,41]$. Notably, target cells of B19V are erythroid cells and erythroid precursors which are shared by $P$. falciparum probably resulting in case of co-infection in more severe anemia [7,21,42-44].

A previous study has shown a high prevalence of B19V and P. falciparum co-infection in Nigeria [7]. In contrast, other studies from Malawi [22], Ghana [8], and Kenya $[20,45]$ found little evidence of acute B19V infection in children (either anemic or control).

In accordance to the study of Nigeria, we could demonstrate that B19V genomes were detectable in $10.28 \%$ of young Gabonese individuals while the frequency of B19V was significantly higher in $P$. falciparum malaria patients than in healthy children $(P<0.001$, Figure 2$)$. Children with severe $P$. falciparum malaria showed the highest rate of $\mathrm{B} 19 \mathrm{~V}$ infection (16.0\%) when compared to mild malaria (12.37\%). These findings suggest that B19V may probably play a role in the pathogenesis of $P$. falciparum malaria following a $\mathrm{B} 19 \mathrm{~V}$ prevalence profile of healthy control < mild malaria < severe malaria. In accordance with our findings on increased B19V detection in $P$. falciparum malaria patients, a previous report suggested that depression of cell-mediated immunity in $P$. falciparum infection might favour co-infection with opportunistic pathogens including B19V [46].

With regard to clinical outcome of $P$. falciparum malaria previous studies have shown a failure of recovery of hemoglobin after effective anti-malarial treatment and delayed recovery of $P$. falciparum malaria after subsidence of B19V infection [3,42]. Furthermore, the association of $\mathrm{B} 19 \mathrm{~V}$ infection with hemoglobin levels may be related to individual variability. Studies have shown previously that a significant decrease in hemoglobin levels can occur in patients with $P$. falciparum malaria $[3,47]$. These findings corroborate well with our observation of significantly lower hematocrit levels in
B19V/P. falciparum co-infected patients in comparison to $P$. falciparum mono-infection $(P<0.05$; Figure 4$)$.

Evaluation of B19V loads, which showed mainly acute B19V-infection due to positive B19V-IgM results (67,86\%), and parasitemia showed no significant differences between mild and severe malaria groups in the studied population possibly postulate that there is no direct or indirect interaction of $\mathrm{B} 19 \mathrm{~V}$ and $P$. falciparum with regards to viral replication. However, a slightly but not significant increase in parasitemia could be observed in mild malaria co-infected with B19V in comparison to mono-infection of $P$. falciparum ( $P>0.05$; Table 1$)$.

Different genotypes of viruses, such as human immunodeficiency virus (HIV) and hepatitis B and $C$ viruses, show different susceptibility to disease progression or response to antiviral treatment. We therefore analysed the distribution of B19V-genotypes in the studied $P$. falciparum patients. Only Erythrovirus (B19V)-genotypes 1 and 2 were observed in the studied population, however genotype 3 cannot be observed in our study population. B19Vgenotype 1 , and especially B19V-genotype $1 \mathrm{~A}$, was the most prevalent genotype in Gabonese children. This is in accordance with previous studies showing a predominance of B19V-genotype 1 worldwide [31,35,48,49]. Interestingly, B19V genotype 2 was found in $28.6 \%$ of the young Gabonese children. These findings were unexpected as recent reports indicated that B19V-genotype 1 and 2 follow an age-dependent distribution while B19V genotype 1 is detectable mainly in younger people ( $<45$ years) and genotype 2 can mostly be observed in patients older than 60 years [15,50]. However, a geographical distribution of B19V genotype 2 could not be completely excluded as it has been shown for genotype 3 [51].

We did not observe any significant differences in parasitemia, hemoglobin and hematocrit levels of $P$. falciparum malaria patients across the different B19V genotypes 1 and 2 . However, genotype 2 was detected significantly more often in children with severe-malaria compared to children with mild-malaria $(\mathrm{P}<0.05)$. The 
detected association of B19V-genotype 2 with severe malaria needs further analysis, although, one can postulate that variability in the host immune response to distinct B19V-genotypes may correspond with the severity of anemia in B19V/P. falciparum patients.

\section{Conclusions}

Overall to our knowledge this is the first study which supports the hypothesis that an acute B19V infection can modulate the clinical course of P. falciparum malaria in Gabonese children. Additionally, our results point towards increased B19V co-infection among young children with P. falciparum malaria. Two of the three Erythrovirus genotypes are detected in these populations while genotype 2 remained more frequent in children with severe malaria. The hematocrit levels of B19V/P. falciparum coinfected mild-malaria patients were significantly decreased as a consequence of co-infection. These findings indicate that the clinical outcome of $P$. falciparum malaria in Gabonese children is influenced by B19V co-infection and should be considered as a diagnostic measure in patients with worsening anemia and persistent fever in spite of effective anti-malarial therapy. However the precise molecular mechanisms involved in B19V co-infection in the context of pathogenesis of $P$. falciparum malaria yet needs to be understood and warrants further analysis.

\section{Abbreviations}

B19V: Parvovirus B19; PCR: Polymerase chain reaction; $n$ PCR: nested PCR QPCR: quantitative real time PCR; ELISA: Enzyme-linked immunosorbent assay.

\section{Competing interests}

The authors declare that they have no competing interests.

\section{Authors' contributions}

PGK, RK, NLT, and CTB conceived the study and designed the research; HVL, NTB, VQB, and TPV participated in developing study instruments; NLT, BTS. LHS, and TPV conducted the research; NLT, BTS, and TPV performed statistical analysis; PGK, RK, NLT, LHS, BTS, TPV and CTB participated in writing and helped to draft the manuscript. All authors read and approved the final manuscript.

\section{Acknowledgements \\ We are grateful to the young patients in Gabon, Africa, and the people of the Albert Schweitzer Hospital involved in their recruitment. We thank Prof. Thanh Hoa Le, Vietnam Academy of Science and Technology (VAST), Hanoi, Vietnam, for his valuable help of the phylogenetic analysis. This work was supported by the Deutsche Forschungsgemeinschaft SFB/Transregio-19, TP B5. NLT and BTS were supported by a scholarship from project 322 of Vietnam Ministry of Education and Training, Viet Nam. The authors acknowledge the support by the Deutsche Forschungsgemeinschaft (DFG) and Open Access Publishing Fund of Tuebingen University.}

\section{Author details}

'Department of Molecular Pathology, Institute of Pathology and Neuropathology, University of Tuebingen, Tuebingen, Germany. ${ }^{2}$ Vietnam Military Medical University, Ha Dong, Ha Noi, Viet Nam. ${ }^{3}$ Tran Hung Dao Hospital, 108 Institute of Clinical Medical and Pharmaceutical Sciences, Ha Noi, Viet Nam. ${ }^{4}$ Vietnam Military Medical Bureau, Ha Noi, Viet Nam. ${ }^{5}$ Institute of Tropical Medicine, University of Tübingen, Tübingen, Germany. ${ }^{6}$ Centre de Recherche Médicale de Lambaréné (CERMEL), Lambaréné P.B.118, Gabon. ${ }^{7}$ Robert Koch Institute, Nordufer 20, D-13353 Berlin, Germany.
Received: 21 December 2012 Accepted: 9 August 2013

Published: 15 August 2013

\section{References}

1. Koukouikila-Koussounda F, Ntoumi F, Ndounga M, Tong HV, Abena AA, Velavan TP: Genetic evidence of regulatory gene variants of the STAT6, IL10R and FOXP3 locus as a susceptibility factor in uncomplicated malaria and parasitaemia in Congolese children. Malar J 2013, 12:9.

2. Miller LH, Baruch DI, Marsh K, Doumbo OK: The pathogenic basis of malaria. Nature 2002, 415(6872):673-679.

3. Lortholary O, Eliaszewicz M, Dupont B, Courouce AM: Parvovirus B19 infection during acute Plasmodium falciparum malaria. Eur J Haematol 1992, 49(4):219.

4. Wildig J, Mueller I, Kiniboro B, Maraga S, Siba P, Cossart Y: Seroprevalence of antibodies to parvovirus B19 among children in Papua New Guinea. Am J Trop Med Hyg 2007, 77(2):354-357.

5. Bonsch C, Kempf C, Mueller I, Manning L, Laman M, Davis TM, Ros C: Chloroquine and its derivatives exacerbate B19V-associated anemia by promoting viral replication. PLoS Negl Trop Dis 2010, 4(4):e669.

6. Ingrassia F, Gadaleta A, Maggi P, Pastore G: Plasmodium falciparum malaria and Parvovirus B19; a case of acute co-infection. BMC Infect Dis 2010, 10:87.

7. Jones PH, Pickett LC, Anderson MJ, Pasvol G: Human parvovirus infection in children and severe anaemia seen in an area endemic for malaria. J Trop Med Hyg 1990, 93(1):67-70.

8. Duedu KO, Sagoe KW, Ayeh-Kumi PF, Affrim RB, Adiku T, Huat LB: The effects of co-infection with human parvovirus B19 and Plasmodium falciparum on type and degree of anaemia in Ghanaian children. Asian Pac J Trop Biomed 2013, 3(2):129-139.

9. Kelly HA, Siebert D, Hammond R, Leydon J, Kiely P, Maskill W: The age-specific prevalence of human parvovirus immunity in Victoria, Australia compared with other parts of the world. Epidemiol Infect 2000, 124(3):449-457.

10. Heegaard ED, Brown KE: Human parvovirus B19. Clin Microbiol Rev 2002, 15(3):485-505

11. Young NS, Brown KE: Parvovirus B19. N Engl J Med 2004, 350(6):586-597.

12. Moore TL: Parvovirus-associated arthritis. Curr Opin Rheumatol 2000, 12(4):289-294.

13. Colmegna I, Alberts-Grill N: Parvovirus B19: its role in chronic arthritis. Rheum Dis Clin North Am 2009, 35(1):95-110.

14. Jaroszewicz J, Calle Serrano B, Wursthorn K, Deterding K, Schlue J, Raupach R, Flisiak R, Bock CT, Manns MP, Wedemeyer H, et al: Hepatitis B surface antigen ( $\mathrm{HBsAg}$ ) levels in the natural history of hepatitis $B$ virus (HBV)-infection: a European perspective. J Hepatol 2010, 52(4):514-522

15. Bock CT, Klingel K, Kandolf R: Human parvovirus B19-associated myocarditis. N Engl J Med 2010, 362(13):1248-1249.

16. Dingli D, Pfizenmaier DH, Arromdee E, Wennberg P, Spittell PC, Chang-Miller A, Clarke BL: Severe digital arterial occlusive disease and acute parvovirus B19 infection. Lancet 2000, 356(9226):312-314.

17. Barah F, Vallely PJ, Chiswick ML, Cleator GM, Kerr JR: Association of human parvovirus B19 infection with acute meningoencephalitis. Lancet 2001, 358(9283):729-730.

18. He Z, Zhuang H, Wang X, Song S, Dong Q, Yan J, Buehring GC, Luo G: Retrospective analysis of non-A-E hepatitis: possible role of hepatitis $B$ and C virus infection. J Med Virol 2003, 69(1):59-65.

19. Toan NL, le Song H, Kremsner PG, Duy DN, Binh VQ, Duechting A, Kaiser $H_{4}$ Torresi J, Kandolf R, Bock CT: Co-infection of human parvovirus B19 in Vietnamese patients with hepatitis B virus infection. J Hepatol 2006, 45(3):361-369.

20. Wildig J, Cossart Y, Peshu N, Gicheru N, Tuju J, Williams TN, Newton CR: Parvovirus B19 infection and severe anaemia in Kenyan children: a retrospective case control study. BMC Infect Dis 2010, 10:88.

21. Wildig J, Michon P, Siba P, Mellombo M, Ura A, Mueller I, Cossart Y: Parvovirus B19 infection contributes to severe anemia in young children in Papua New Guinea. J Infect Dis 2006, 194(2):146-153.

22. Yeats J, Daley H, Hardie D: Parvovirus B19 infection does not contribute significantly to severe anaemia in children with malaria in Malawi. Eur J Haematol 1999, 63(4):276-277.

23. Morinet F: Parvovirus B19 infection. Pathol Biol (Paris) 1992, 40(6):621-622. 
24. Kalmbach $Y$, Boldt $A B$, Fendel $R$, Mordmuller $B$, Kremsner $P G$, Kun JF: Increase in annexin V-positive B cells expressing LILRB1/ILT2/CD85j in malaria. Eur Cytokine Netw 2006, 17(3):175-180.

25. Kun JF, Schmidt-Ott RJ, Lehman LG, Lell B, Luckner D, Greve B, Matousek P, Kremsner PG: Merozoite surface antigen 1 and 2 genotypes and rosetting of Plasmodium falciparum in severe and mild malaria in Lambarene, Gabon. Trans R Soc Trop Med Hyg 1998, 92(1):110-114.

26. Kun JF, Klabunde J, Lell B, Luckner D, Alpers M, May J, Meyer C, Kremsner PG: Association of the ICAM-1Kilifi mutation with protection against severe malaria in Lambarene. Gabon. Am J Trop Med Hyg 1999, 61(5):776-779.

27. Kun JF, Mordmuller B, Lell B, Lehman LG, Luckner D, Kremsner PG: Polymorphism in promoter region of inducible nitric oxide synthase gene and protection against malaria. Lancet 1998, 351(9098):265-266.

28. Kremsner PG, Radloff P, Metzger W, Wildling E, Mordmuller B, Philipps J, Jenne L, Nkeyi M, Prada J, Bienzle U, et al: Quinine plus clindamycin improves chemotherapy of severe malaria in children. Antimicrob Agents Chemother 1995, 39(7):1603-1605.

29. Velavan TP, Buyukyazici B, Kremsner PG, Kun JF: Combined promoter haplotypes of the IL10R genes are associated with protection against severe malaria in Gabonese children. Immunogenetics 2012, 64(2):87-95.

30. Bultmann BD, Klingel K, Sotlar K, Bock CT, Baba HA, Sauter M, Kandolf R: Fatal parvovirus B19-associated myocarditis clinically mimicking ischemic heart disease: an endothelial cell-mediated disease. Hum Pathol 2003, 34(1):92-95.

31. Toan NL, Duechting A, Kremsner PG, le Song H, Ebinger M, Aberle $S$, Binh VQ, Duy DN, Torresi J, Kandolf R, et al: Phylogenetic analysis of human parvovirus B19, indicating two subgroups of genotype 1 in Vietnamese patients. J Gen Virol 2006, 87(Pt 10):2941-2949.

32. Tschope C, Bock CT, Kasner M, Noutsias M, Westermann D, Schwimmbeck PL, Pauschinger M, Poller WC, Kuhl U, Kandolf R, et al: High prevalence of cardiac parvovirus B19 infection in patients with isolated left ventricular diastolic dysfunction. Circulation 2005, 111(7):879-886.

33. Tamura K, Peterson D, Peterson N, Stecher G, Nei M, Kumar S: MEGA5: molecular evolutionary genetics analysis using maximum likelihood, evolutionary distance, and maximum parsimony methods. Mol Biol Evol 2011, 28(10):2731-2739.

34. Saitou N, Nei M: The neighbor-joining method: a new method for reconstructing phylogenetic trees. Mol Biol Evol 1987, 4(4):406-425.

35. Servant A, Laperche S, Lallemand F, Marinho V, De Saint MG, Meritet JF, Garbarg-Chenon A: Genetic diversity within human erythroviruses: identification of three genotypes. J Virol 2002, 76(18):9124-9134.

36. Freitas RB, Melo FL, Oliveira DS, Romano CM, Freitas MR, Macedo O, Linhares AC, De AZPM, Durigon EL: Molecular characterization of human erythrovirus B19 strains obtained from patients with several clinical presentations in the Amazon region of Brazil. J Clin Virol 2008, 43(1):60-65.

37. Sanabani S, Neto WK, Pereira J, Sabino EC: Sequence variability of human erythroviruses present in bone marrow of Brazilian patients with various parvovirus B19-related hematological symptoms. J Clin Microbiol 2006, 44(2):604-606

38. Greenwood BM, Bradley AK, Greenwood AM, Byass P, Jammeh K, Marsh K, Tulloch S, Oldfield FS, Hayes R: Mortality and morbidity from malaria among children in a rural area of The Gambia, West Africa. Trans $R$ Soc Trop Med Hyg 1987, 81(3):478-486.

39. Menendez C, Fleming AF, Alonso PL: Malaria-related anaemia. Parasitol Today 2000, 16(11):469-476.

40. Manning L, Laman M, Rosanas-Urgell A, Michon P, Aipit S, Bona C, Siba P, Mueller I, Davis TM: Severe anemia in Papua New Guinean children from a malaria-endemic area: a case-control etiologic study. PLoS Negl Trop Dis 2012, 6(12):e1972.

41. Brown K: Anaemia, parvovirus, and malaria. Lancet 2006, 368(9537):714-716.

42. Scarlata F, Gianelli E, Miceli S, Galimberti L, Antinori S: Acute parvovirus B19 infection and anemia during Plasmodium falciparum malaria. Clin Infect Dis 2002, 35(11):1449-1451.

43. Rios M, Bianco C: The role of blood group antigens in infectious diseases. Semin Hematol 2000, 37(2):177-185.

44. Gupta R, Singh T: Parvovirus B19 co-infection with falciparum malaria: a cause of severe anemia. Haematologica 2005, 90(12 Suppl):ECR41.
45. Newton CR, Warn PA, Winstanley PA, Peshu N, Snow RW, Pasvol G, Marsh K: Severe anaemia in children living in a malaria endemic area of Kenya. Trop Med Int Health 1997, 2(2):165-178.

46. Ho M, Webster HK, Looareesuwan S, Supanaranond W, Phillips RE, Chanthavanich P, Warrell DA: Antigen-specific immunosuppression in human malaria due to Plasmodium falciparum. J Infect Dis 1986, 153(4):763-771.

47. Urganci N, Arapoglu M, Kayaalp N: Plasmodium falciparum malaria with coexisting parvovirus B19 infection. Indian Pediatr 2003, 40(4):369-370.

48. Candotti D, Etiz N, Parsyan A, Allain JP: Identification and characterization of persistent human erythrovirus infection in blood donor samples. J Virol 2004, 78(22):12169-12178.

49. Opaleye $\mathrm{OO}$, Fagbami AH, Lalremruata A, Kun JF: Prevalence and association of human parvovirus B19V with hepatitis B and $C$ viruses in Nigeria. J Med Virol 2011, 83(4):710-716.

50. Norja P, Hokynar K, Aaltonen LM, Chen R, Ranki A, Partio EK, Kiviluoto O, Davidkin I, Leivo T, Eis-Hubinger AM, et al: Bioportfolio: lifelong persistence of variant and prototypic erythrovirus DNA genomes in human tissue. Proc Natl Acad Sci U S A 2006, 103(19):7450-7453.

51. Slavov SN, Kashima S, Silva-Pinto AC, Covas DT: Genotyping of Human parvovirus B19 among Brazilian patients with hemoglobinopathies. Can J Microbiol 2012, 58(2):200-205.

doi:10.1186/1471-2334-13-375

Cite this article as: Toan et al:: Co-infection of human parvovirus B19 with Plasmodium falciparum contributes to malaria disease severity in Gabonese patients. BMC Infectious Diseases 2013 13:375.

\section{Submit your next manuscript to BioMed Central and take full advantage of:}

- Convenient online submission

- Thorough peer review

- No space constraints or color figure charges

- Immediate publication on acceptance

- Inclusion in PubMed, CAS, Scopus and Google Scholar

- Research which is freely available for redistribution 